\title{
Learning from diagnostic errors to improve patient safety when GPs work in or alongside emergency departments: incorporating realist methodology into patient safety incident report analysis
}

\author{
Alison Cooper ${ }^{1 *}$, Andrew Carson-Stevens ${ }^{1}$, Matthew Cooke ${ }^{2}$, Peter Hibbert ${ }^{3}$, Thomas Hughes ${ }^{4}$, Faris Hussain ${ }^{1}$,
} Aloysius Siriwardena ${ }^{5}$, Helen Snooks ${ }^{6}$, Liam J. Donaldson ${ }^{7}$ and Adrian Edwards ${ }^{1}$

\begin{abstract}
Background: Increasing demand on emergency healthcare systems has prompted introduction of new healthcare service models including the provision of GP services in or alongside emergency departments. In England this led to a policy proposal and $£ 100$ million (US\$130million) of funding for all emergency departments to have co-located GP services. However, there is a lack of evidence for whether such service models are effective and safe. We examined diagnostic errors reported in patient safety incident reports to develop theories to explain how and why they occurred to inform potential priority areas for improvement and inform qualitative data collection at case study sites to further refine the theories.

Methods: We used a mixed-methods design using exploratory descriptive analysis to identify the most frequent and harmful sources of diagnostic error and thematic analysis, incorporating realist methodology to refine theories from an earlier rapid realist review, to describe how and why the events occurred and could be mitigated, to inform improvement recommendations. We used two UK data sources: Coroners' reports to prevent future deaths (30.7.13-14.08.18) and National Reporting and Learning System (NRLS) patient safety incident reports (03.01.0530.11.15).

Results: Nine Coroners' reports (from 1347 community and hospital reports, 2013-2018) and 217 NRLS reports (from 13 million, 2005-2015) were identified describing diagnostic error related to GP services in or alongside emergency departments. Initial theories to describe potential priority areas for improvement included: difficulty identifying appropriate patients for the GP service; under-investigation and misinterpretation of diagnostic tests; and inadequate communication and referral pathways between the emergency and GP services. High-risk presentations included: musculoskeletal injury, chest pain, headache, calf pain and sick children.
\end{abstract}

\footnotetext{
* Correspondence: CooperA8@cardiff.ac.uk

'Division of Population Medicine, School of Medicine, Cardiff University, Cardiff, UK

Full list of author information is available at the end of the article
}

C C The Author(s). 2021 Open Access This article is licensed under a Creative Commons Attribution 4.0 International License, which permits use, sharing, adaptation, distribution and reproduction in any medium or format, as long as you give appropriate credit to the original author(s) and the source, provide a link to the Creative Commons licence, and indicate if changes were made. The images or other third party material in this article are included in the article's Creative Commons licence, unless indicated otherwise in a credit line to the material. If material is not included in the article's Creative Commons licence and your intended use is not permitted by statutory regulation or exceeds the permitted use, you will need to obtain permission directly from the copyright holder. To view a copy of this licence, visit http://creativecommons.org/licenses/by/4.0/ The Creative Commons Public Domain Dedication waiver (http://creativecommons.org/publicdomain/zero/1.0/) applies to the data made available in this article, unless otherwise stated in a credit line to the data. 
Conclusion: Initial theories include the following topics as potential priority areas for improvement interventions and evaluation to minimise the risk of diagnostic errors when GPs work in or alongside emergency departments: a standardised initial assessment with streaming guidance based on local service provision; clinical decision support for high-risk conditions; and standardised computer systems, communication and referral pathways between emergency and GP services. These theories require refinement and testing with qualitative data collection from case study (hospital) sites.

Keywords: Patient safety, Diagnostic error, General practitioners, Emergency department

\section{Background}

Increasing demand on emergency healthcare systems has prompted the introduction of new service models, including provision of General Practitioner (GP) services in or alongside emergency departments [1]. In England this led to a policy proposal and $£ 100$ million (US\$130million) of funding for all emergency departments to have co-located GP services [2]. The aim of this initiative was to reduce waiting times and overcrowding and therefore improve overall patient care and safety $[3,4]$, however, there is a lack of evidence about potential patient safety risks associated with these service models and how these could be mitigated $[5,6]$.

Estimates for the number of patients presenting to emergency departments with primary care type problems that can be dealt with by GPs vary from 10 to $43 \%$, depending on definitions and population groups [7-13]. There are several different models of GP service provision associated with emergency departments: INSIDE the emergency department, either integrated with the emergency medicine service or in a separate parallel service; or OUTSIDE the emergency department, either on or off site [14]. These models may function on a spectrum from being closer to an emergency medicine service or to usual primary care service provision. As well as GPs, the service may also include nurse practitioners and other primary care healthcare professionals [14].

Emergency departments are high-risk settings for diagnostic errors that may result in significant patient harm $[15,16]$. The World Health Organization has also identified diagnostic errors in primary care as a high-priority problem [17]. GPs traditionally have different diagnostic approaches to emergency medicine clinicians. They rely less on acute investigations $[8,18]$, and may have different approaches or cognitive biases from working in lower risk settings [19]. There is little research evidence to guide decisions about how GP service models in or alongside emergency departments can be most effective and safe, and how to minimise the risk of diagnostic errors $[5,6,20,21]$.

Patient safety incident reports can be aggregated to generate data summaries describing the most frequent and harmful incident types while thematic analysis of individual report texts can be used to explore how and why such incidents may occur and identify contributing factors that can be targeted to mitigate future events [22]. Studies of incident reports using this approach have been used to develop improvement recommendations to prevent safety-related hospital deaths [23], the treatment of children in primary care [24], and diagnostic errors in undifferentiated emergency department attendances [25].

This work was part of a wider NIHR funded realist evaluation evaluating the effectiveness of GPs working in or alongside emergency departments [26], conducted following a rapid realist review of the effectiveness of GPs working in or alongside emergency departments [6]. Realist methodology includes learning from 'nuggets of information' to explain what works, for whom, how and in what circumstances to generate theories described as context-mechanism-outcome configurations (CMOs) $[27,28]$. We aimed to analyse two UK data sources of patient safety incident reports to: characterise the nature of diagnostic errors related to these GP services; refine theories developed from the rapid realist review to explain how and why these incidents occurred to inform qualitative data collection and subsequent theory testing at hospital case study sites; and inform improvement recommendations.

\section{Methods}

We conducted a four-stage sequential exploratory mixedmethods analysis of two UK national data sources: Coroners' reports to prevent future deaths, and patient safety incident reports from the National Learning and Reporting System (NRLS). This notably incorporated realist principles as follows:

\section{Familiarisation of report content and} application of codes from the PISA frameworks to create coded summaries of report narratives [22].

2. Generation of data summaries using exploratory descriptive statistics to describe the frequency and burden (harm) of incident types and key relationships with contributory factors.

3. Interpretation of themes and learning through a thematic analysis of reports aggregated by common characteristics from step 2 . We used realist methodology to infer why incidents may have occurred to identify additional contributing factors which were not explicit from report narratives read in isolation. We identified mechanisms (M) that explained how or why contexts $(\mathrm{C})$ related to outcomes $(\mathrm{O})$ to develop theories described as 
context-mechanism-outcome configurations (CMOs), definitions in Table $1[27,28]$.

4. As per realist methodology, an additional stage of stakeholder expert feedback was added to validate findings.

\section{Data sources}

\section{Coroners' reports to prevent future deaths}

According to the Coroners and Justice Act 2009, Coroners have a statutory duty to make reports to a person, organisation, local authority, government department or agency if they believe that action should be taken to prevent future deaths [29]. All reports and responses must be sent to the Chief Coroner and most cases are summarised and published on the Courts and Tribunals Judiciary publicly available website [30].

\section{National Reporting and learning System (NRLS) patient safety incident reports}

The NRLS is a database of over 18 million patient safety incident reports, usually reported by staff, from healthcare organisations in England and Wales. A patient safety incident is defined as, "any unintended or unexpected incident that could have harmed or did harm a patient during healthcare delivery" [31]. Reporting began voluntarily in 2003 but, since 2010, it has been mandatory to report any incident that resulted in severe patient harm or death. Since the inception of the NRLS, reporting arrangements have included batch returns via local risk management systems, and more recently in England, by direct notification to the Care Quality Commission (an independent regulator of all health and social care services in England). Reports contain anonymised, structured information about location, patient demographics, and the reporter's perception of harm severity, complemented by unstructured free-text descriptions of the incident, potential contributory factors, and planned actions to prevent reoccurrence.

Table 1 Realist definitions $[27,28]$

$\begin{array}{ll}\begin{array}{l}\text { Realist definitions } \\ \text { Context (C) }\end{array} & \begin{array}{l}\text { Pre-existing conditions which influence the success or } \\ \text { failure of different interventions or programmes }\end{array} \\ \begin{array}{ll}\text { Mechanism } & \begin{array}{l}\text { Characteristics of the intervention and people's reaction } \\ \text { to it; how it influences their reasoning }\end{array} \\ \text { Outcome (O) } & \begin{array}{l}\text { Intended and unintended results of the intervention as } \\ \text { a result of a mechanism operating within a context }\end{array} \\ \text { Initial rough } & \begin{array}{l}\text { An early theory, informed by available evidence, about } \\ \text { how, why, for whom, and in what circumstances the } \\ \text { intervention is thought to work described as a context- } \\ \text { mechanism-outcome (CMO) configuration }\end{array} \\ \text { Refined theory } & \begin{array}{l}\text { An initial theory that has been refined using primary or } \\ \text { secondary evidence }\end{array} \\ \hline\end{array}\end{array}$

\section{Sampling strategy}

Pilot work was conducted in January 2017 to identify a sample of NRLS reports regarding GP services in or alongside emergency departments, but most were irrelevant referring to the GP as part of the patient's journey rather than the GP service. Since the sample of identified Coroners' reports all described diagnostic error, although infrequent, we included these recognised patient safety incident data as they record the highest level of patient harm and may be especially informative.

\section{Coroners' reports to prevent future deaths}

We reviewed all reports available in the 'Community health care and emergency services related deaths', 'Hospital Death' and 'Child Death' categories (2013-2018) on the Courts and Tribunals Judiciary website in August 2018. Reports were selected if they were related to GP service provision in or alongside emergency departments (inclusion and exclusion criteria shown in Table 2).

\section{National Reporting and learning System (NRLS) patient safety incident reports}

NRLS reports were available from 03/01/05-30/11/15, stored on a secure computer platform at Cardiff University. We filtered reports with structured electronic variables (pre-specified by the reporter or their organisation before submission to the NRLS) for emergency and urgent care settings (PD05); then the free-text with primary care terms to identify reports regarding GP services in these settings; then using structured variables for diagnostic error as defined by the reporter (IN05), Fig. 1. Searches were conducted July-September 2018. After this threestage filtering process, we read the reports to determine if they were related to GP service provision in or alongside emergency departments (Table 2).

\section{Data analysis \\ Familiarisation and data coding}

We coded reports from both datasets using the multiaxial PISA classification system based on the recursive model for incident analysis and aligned to the four major classes of information advocated by the World Health Organisation International Classification for Patient Safety [22]. This involved reading the free text component of

Table 2 Inclusion and exclusion criteria

Inclusion criteria
- Reports describing diagnostic errors related to GP services in or
alongside emergency departments
Exclusion criteria
- Reports involving community 'in-hours' or 'out-of-hours' GP service
provision not occurring at the same geographical location either
within or alongside emergency departments
- Diagnostic errors occurring during usual emergency department
service provision




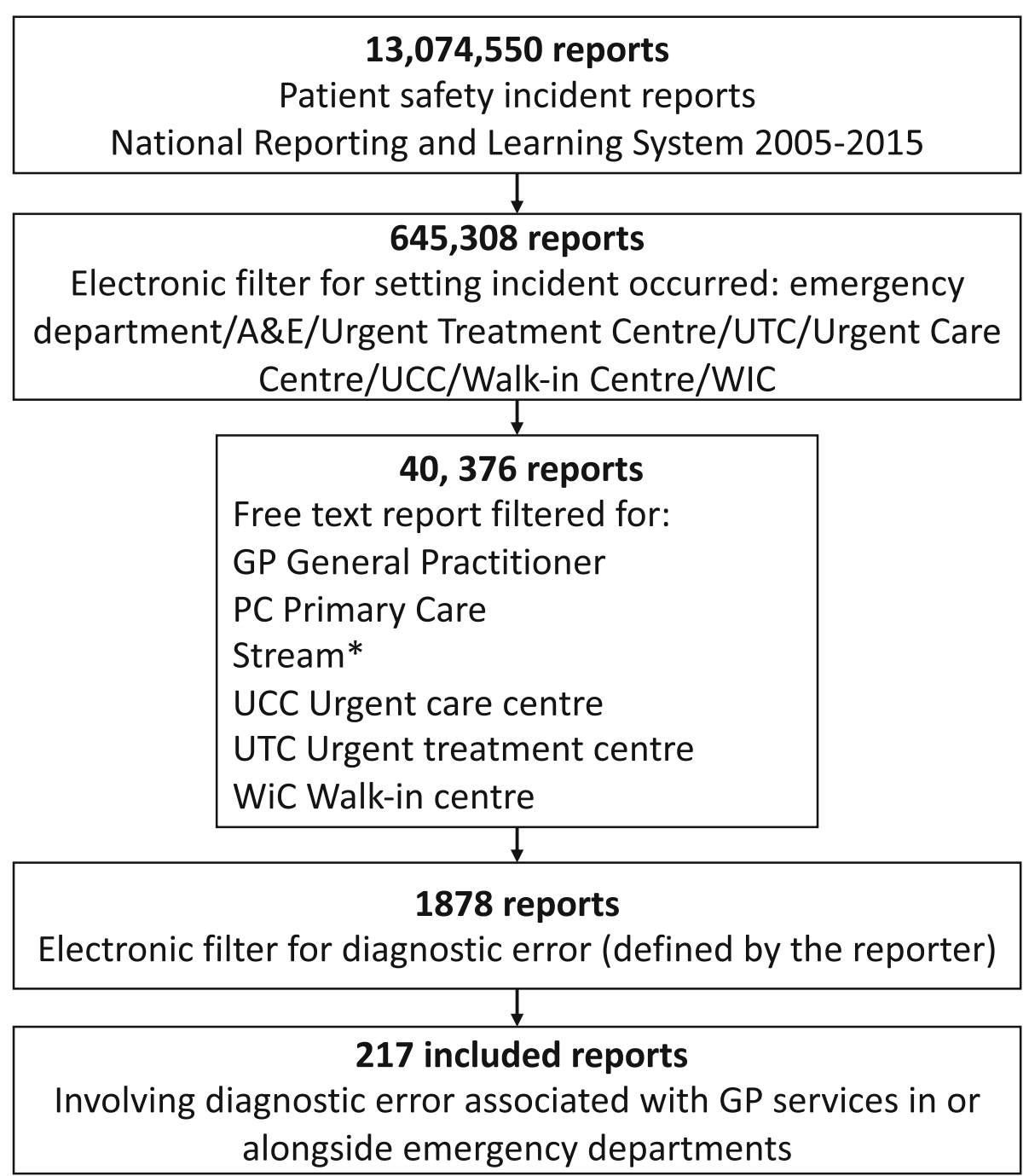

Fig. 1 National Reporting and Learning System patient safety incident reports, search strategy and results

each report and coding information in relation to: the primary safety incident that was reported to have directly affected patient care (e.g. diagnostic error); the chain of incidents leading up to the safety incident (e.g. misinterpretation of X Ray); other independent contributory factors (e.g. unusual patient presentation); and reported patient harm outcomes with harm severity classified from the free text report according to WHO International Classification for Patient Safety definitions [32]. We classified diagnostic errors according to the Society to Improve Diagnosis in Medicine (Table 3) [33]. The primary coder was an experienced GP and patient safety qualitative researcher (AC). A medical student $(\mathrm{FH})$ double coded the NRLS reports $(259 / 1878,14 \%)$ and took part in coding meetings to clarify the recursive model approach, the nature of the codes and discuss complex cases. FH was working on a parallel study analysing NRLS reports describing diagnostic error associated with usual emergency department care [25]. The Cohen's kappa showed acceptable moderate agreement (0.51) between coders.

\section{Generation of data summaries}

We exported the codes into Microsoft Excel for mac (version 16.35) and used pivot tables to undertake an exploratory descriptive analysis to assess the nature of the diagnostic error and the most frequent and harmful presenting conditions from both datasets, the associated chain of incidents, and other contributory factors. We summarised the most commonly identified causes and potential interventions in a driver diagram [34]. This is a quality improvement tool to summarise priority areas for change and to map potential interventions. 
Table 3 Diagnostic error definitions [33]

\begin{tabular}{ll}
\hline $\begin{array}{l}\text { Diagnostic error definitions } \\
\text { Diagnostic } \\
\text { error }\end{array}$ & $\begin{array}{l}\text { The failure to (a) establish an accurate and timely } \\
\text { explanation of the patient's health problem(s) or (b) } \\
\text { communicate that explanation to the patient. }\end{array}$ \\
$\begin{array}{ll}\text { Wrong } \\
\text { diagnosis }\end{array}$ & $\begin{array}{l}\text { Occurs, for example, if a patient truly having a heart } \\
\text { attack is told their pain is from gastro-oesophageal }\end{array}$ \\
$\begin{array}{l}\text { Delayed } \\
\text { diagnosis }\end{array}$ & $\begin{array}{l}\text { The diagnosis should have been made earlier. } \\
\text { Missed } \\
\text { diagnosis }\end{array}$ \\
\hline
\end{tabular}

\section{Thematic analysis and realist theory development}

We then used thematic analysis to identify and describe recurring themes within and between datasets (not captured by the quantitative data) that could be targeted to mitigate future similar incidents, incorporating realist methodology to infer why incidents may have occurred, to whom, in what circumstances and why. We used the initial rough theories developed from the rapid realist review as a template for mapping supporting data on the Microsoft Excel spreadsheet [6]. If the data gave additional information to explain how and why the event may have occurred, we incorporated this information into the $\mathrm{CMO}$ configuration to refine the theory. New information, not included in the initial rough theories from the review, was used to develop new initial theories.

\section{Stakeholder feedback}

We presented findings to the wider 'GPs in EDs' team for feedback: including patient safety experts, patient representatives, primary care and emergency department clinicians (TH, PH, ACS, FD, ME, PA, JH, BE) at a study meeting in November 2018. Feedback was strongly supportive. We also carried out literature searches to determine whether existing interventions or initiatives for promoting patient safety had been described in each area and aligned these with the driver diagram intervention areas. When available, the strength of each intervention was graded using the US Department of Veterans Affairs classification, where the strongest designs are permanent and physical rather than temporary and procedural [35].

\section{Results}

\section{Coroners' reports to prevent future deaths}

We screened 1347 Coroners' reports to prevent future deaths classified as "Community health care and emergency services" and "Hospital deaths" over the five-year period. From these we identified nine cases which included diagnostic errors related to GP service provision in or alongside emergency departments (summarised in Table 4). No new cases were identified in the "Child
Death" category (with some duplication of cases found in the other sections).

Seven of these reports described a wrong diagnosis with a lack of referral for investigation on initial presentation. Three main conditions were identified: venothrombotic events presenting with calf pain or shortness of breath $(n=3)$; cardiac death with a presentation of chest pain $(n=2)$; and intracranial haemorrhage following a head injury $(n=2)$. Another report described delayed initial assessment and diagnosis for a patient, which was felt to have contributed towards his death by sepsis. A further report described a missed diagnosis where a lack of communication about recurrent attendances from a walk-in centre was thought to have contributed to the death of a baby with pneumonia.

Root cause analysis and expert opinions were often detailed in the reports, giving understanding of the factors that may have contributed to the diagnostic errors. Patient characteristics included those presenting with rare conditions, for example Loeys-Dietz syndrome (thoracic aortic aneurysm), or others presenting with an atypical pattern of signs and symptoms, including no leg swelling in a patient presenting with a deep vein thrombosis or a young female with chest pain. The possibility of cognitive biases affecting the clinical reasoning of GPs who may usually work in community settings, with a lower probability of serious disease, was raised in one expert opinion. Organisational factors that may have contributed towards diagnostic errors included: lack of clear streaming guidance for patients presenting with high-risk conditions; unclear referral pathways for patients sent in for further investigation by their local GP; and communication barriers between primary and secondary care.

\section{National Reporting and learning System reports}

Over the ten-year period, 1878 reports were identified in the filtered sample and screened. Irrelevant and duplicate reports were excluded resulting in an included sample of 217 reports describing diagnostic errors with learning related to GP service provision in or alongside emergency departments (see Fig. 1).

The reports were generally brief, with limited information about contributory events, and most did not describe the patient harm outcome resulting from the diagnostic errors $(n=188)$. In those reports where harm could be ascertained, 11 reports described mild or moderate patient harm, 12 described severe harm and six described events leading to death. Three of the six reports describing a death involved patients presenting with headaches. From the nature of the serious diagnoses involved (Table 5), for those reports without harm descriptions, patient harm appears likely. 
Table 4 Summary of Coroners' reports to prevent future deaths related to GP service provision in or alongside emergency departments (9 reports identified from 1347 reports, 2013-2018)

\begin{tabular}{lllll}
\hline $\begin{array}{l}\text { Report } \\
\text { number }\end{array}$ & $\begin{array}{l}\text { Presenting } \\
\text { symptom }\end{array}$ & $\begin{array}{l}\text { Initial } \\
\text { diagnosis }\end{array}$ & $\begin{array}{l}\text { Actual } \\
\text { diagnosis }\end{array}$ & Summary of report \\
\hline $\begin{array}{llll}\text { 1. Wrong } \\
\text { diagnosis }\end{array}$ & Calf pain & $\begin{array}{l}\text { Muscular } \\
\text { injury }\end{array}$ & $\begin{array}{l}\text { Deep vein } \\
\text { thrombosis } \\
\text { (DVT) }\end{array}$ & $\begin{array}{l}\text { A 47-year-old woman presented to the ur- } \\
\text { gent care centre with calf pain. She had a } \\
\text { strong family history of DVT but this was not } \\
\text { elicited in the history and she was diagnosed } \\
\text { with muscular pain. She later died from a pul- } \\
\end{array}$ \\
& & & monary embolism.
\end{tabular}

Key learning from reports

"The A\&E expert gave evidence that patients presenting to an urgent care centre, walk in centre or out of hours are a much higher risk group than those who present to their own GP surgery. As a consequence, there must be clinically agreed protocols that at the front end of any facility that receives undifferentiated patients that manage this higher risk population. Patients that present with certain high risk conditions such as chest pain, shortness of breath or calf pain must be directed to a facility that can exclude serious illness and this is usually the nearest A\&E."

\begin{tabular}{|c|c|c|}
\hline $\begin{array}{l}\text { 2. Wrong } \\
\text { diagnosis }\end{array}$ & Calf pain & $\begin{array}{l}\text { Muscular } \\
\text { injury }\end{array}$ \\
\hline
\end{tabular}

A man presented to a walk in centre with calf pain following a driving holiday in France. There was no calf swelling or tenderness and he was diagnosed with a musculoskeletal injury. He was then seen by his own GP a further 3 times but the walk in centre records were not available. He later died of a pulmonary embolism.
3. Wrong Shortness Not Pulmonary diagnosis of breath

\section{A 44-year-old man presented to A\&E and was} streamed to the GP. He died from a pulmonary embolism two days later.
(PE)
"Records of the August appointment (to the walk-in centre) were not available."

"Mr (), died of a pulmonary embolism having been diverted from accident and emergency assessment 2 days prior to his death. This

\begin{tabular}{|c|c|c|c|c|}
\hline $\begin{array}{l}\text { 4. Wrong } \\
\text { diagnosis }\end{array}$ & Chest pain & $\begin{array}{l}\text { Non-cardiac } \\
\text { chest pain }\end{array}$ & $\begin{array}{l}\text { Adult } \\
\text { Cardiac } \\
\text { Death } \\
\text { Syndrome }\end{array}$ & $\begin{array}{l}\text { A 30-year-old woman presented to the ambu- } \\
\text { lance service with chest pain, normal examin- } \\
\text { ation and ECG. She chose to see her GP who } \\
\text { thought the pain was non-cardiac, she died a } \\
\text { few hours later at home. }\end{array}$ \\
\hline
\end{tabular}

5. Wrong Chest pain Gastritis diagnosis Syndrome seen by an ambulance, had a normal ECG meant that further tests, which could have led to an earlier diagnosis for his condition were not done. No 111 referral information was available to 'Front door' or the ED (emergency department)."

"Mrs Y, aged 30 with a family history of heart disease, was seen by ambulance staff with chest pain, and examination and ECG were reported as normal. The GP had not considered the possibility of Sudden Adult Death Syndrome"

"Crucially, the only piece of the patient's presenting history which wasn't passed on (to the ED doctor from the local GP) was that the pain that she was feeling was the (thoracic and chose to see her GP for review. She was aneurysm) seen by the local GP and referred to A\&E for further investigation. She was streamed to the GP in A\&E who referred her back to A\&E where she was assessed, treated for gastritis and discharged with no further investigations. The patient's presenting history of the same pain as her previous aortic dissection and the initial GP referring letter was lost in transfer. She died a few days later.

6. Wrong Head injury Not Intracranial A man presented to an urgent care centre diagnosis documented haemorrhage

following a head injury and again the following day with headache and vomiting. No CT was done. He collapsed and died the next day.

7. Wrong Head injury Not Extradural A 10-year-old boy presented to A\&E following diagnosis documented haematoma a head injury and was streamed to the urgent GP clinic and discharged. He was seen at home by a paramedic the following day and not brought to hospital. He collapsed the next day whilst waiting to be seen in the GP surgery. He underwent neurosurgery but died a few days later.

8. Unclear n/a Sepsis

A patient presented to the emergency

"Patients undergoing haemodialysis or significant uraemia are at risk of haemorrhage and this is not commonly known within the medical profession or referred to in relevant NICE guidelines."

"The consultant from the department told me, during the course of his evidence, that it would be good practice for all suspected head injuries to be referred to the A\&E team."

"Staffing levels in the emergency 
Table 4 Summary of Coroners' reports to prevent future deaths related to GP service provision in or alongside emergency departments (9 reports identified from 1347 reports, 2013-2018) (Continued)

\begin{tabular}{|c|c|c|c|c|c|}
\hline $\begin{array}{l}\text { Report } \\
\text { number }\end{array}$ & $\begin{array}{l}\text { Presenting } \\
\text { symptom }\end{array}$ & $\begin{array}{l}\text { Initial } \\
\text { diagnosis }\end{array}$ & $\begin{array}{l}\text { Actual } \\
\text { diagnosis }\end{array}$ & Summary of report & Key learning from reports \\
\hline $\begin{array}{l}\text { Delayed } \\
\text { diagnosis }\end{array}$ & & & & $\begin{array}{l}\text { department and was booked into the urgent } \\
\text { care centre. He was not triaged for over } 45 \\
\text { min by which time his condition had } \\
\text { deteriorated. }\end{array}$ & $\begin{array}{l}\text { department were not sufficient to be able to } \\
\text { follow national or any local policy on treating } \\
\text { suspected sepsis." }\end{array}$ \\
\hline $\begin{array}{l}\text { 9. Missed } \\
\text { diagnosis }\end{array}$ & Cough & $\begin{array}{l}\text { Chest } \\
\text { infection }\end{array}$ & Pneumonia & $\begin{array}{l}\text { A 9-month-old baby presented to a walk-in } \\
\text { centre } 3 \text { times over } 3 \text { months with a cough. } \\
\text { She was then seen twice by nurse practi- } \\
\text { tioners at her own surgery with the same } \\
\text { complaint who could not recall having access } \\
\text { to information about the walk in centre visits } \\
\text { and did not refer the patient to the GP. She } \\
\text { died the following month from } \\
\text { bronchopneumonia. }\end{array}$ & $\begin{array}{l}\text { "There appeared to be no guidelines or } \\
\text { triggers for when a practice nurse } \\
\text { (practitioner) should refer a patient be seen } \\
\text { by a doctor." }\end{array}$ \\
\hline
\end{tabular}

Most reports described patients leaving the emergency department with a wrong diagnosis $(n=144)$. These were largely due to errors in clinical decision-making: mis-interpretation of X-Rays later picked up by radiological reporting systems $(n=87)$, or under-investigation of key symptoms $(n=59)$. Other reports described a delayed diagnosis within the emergency department or which was identified at a later date $(n=71)$. Over half of these involved an inadequate triage or streaming process $(n=42)$. Others described inadequate specialist referral pathways from community or emergency department GP services $(n=21)$, or inadequate assessment and

Table 5 Presenting conditions involved in diagnostic errors described in incident reports related to GP service provision in or alongside emergency departments (National Reporting and Learning System reports; 217/13million 2005-2015)

\begin{tabular}{|c|c|c|}
\hline Presenting complaint & Number of NRLS reports & $\begin{array}{l}\text { Examples of conditions involved } \\
\text { (not always stated in the report) }\end{array}$ \\
\hline Musculoskeletal injury & 114 & $\begin{array}{l}114 \text { fractures } \\
7 \text { Hip and } 6 \text { Spinal fractures }\end{array}$ \\
\hline Chest pain & 18 & 15 Acute Coronary Syndrome \\
\hline Unwell child & 15 & 7 sick infants requiring resuscitation level care \\
\hline Headache & 14 & $\begin{array}{l}6 \text { Head injury } \\
5 \text { Subarachnoid haemorrhage } \\
2 \text { Brain tumour }\end{array}$ \\
\hline Abdominal pain & 9 & $\begin{array}{l}3 \text { Appendicitis } \\
1 \text { Ischaemic bowel }\end{array}$ \\
\hline Shortness of breath & 6 & $\begin{array}{l}1 \text { Acute asthma } \\
1 \text { Pneumothorax } \\
1 \text { Respiratory failure } \\
1 \text { Stridor }\end{array}$ \\
\hline Limb pain - no trauma & 4 & $\begin{array}{l}2 \text { Deep vein thrombosis } \\
1 \text { Ischaemic foot }\end{array}$ \\
\hline Collapse & 4 & 1 Cardiac arrest \\
\hline Back pain & 4 & $\begin{array}{l}1 \text { Pulmonary embolism } \\
1 \text { Abdominal Aortic Aneurysm } \\
1 \text { Spinal cord compression }\end{array}$ \\
\hline Limb weakness & 2 & 2 Stroke \\
\hline Eye injury & 2 & 1 Missed foreign body in eye \\
\hline Rash & 2 & 1 Measles \\
\hline Other & 13 & $\begin{array}{l}1 \text { Testicular torsion } \\
1 \text { Ectopic pregnancy } \\
1 \text { Anaphylaxis }\end{array}$ \\
\hline Not documented & 10 & $\begin{array}{l}1 \text { Pneumothorax } \\
1 \text { Trauma case }\end{array}$ \\
\hline Total & 217 & \\
\hline
\end{tabular}


investigation. In this sample there were no reports of missed diagnoses (Society to Improve Diagnosis in Medicine definition, Table 2) [33].

\section{Initial theories developed from both data sources}

We grouped contributory events that led to the diagnostic errors into three themes: difficulty with triage and streaming processes; errors in clinical decision-making including under-investigation and mis-interpretation of results; and organisational factors including inadequate referral pathways and communication between services. These are summarised in the driver diagram, along with interventions that could mitigate future events (see Fig. 2). Theories refined and developed from these data are described as context-mechanism-outcome configurations.

\section{Difficulty with triage and streaming processes}

If patients presenting to the emergency department (C) are assessed for streaming but the streaming nurse is unclear which patients are appropriate (due to unclear guidance or inexperience) (M)

or the initial assessment is inadequate (limited history or lack of basic physiological observations) (M)

then higher risk patients may be streamed to the GP service (O)

*Bold text indicates how this theory was refined from the initial theory in the rapid realist review [6]

One Coroner's preventing future death report and 29 NRLS reports highlighted the difficulty in identifying which patients were appropriate for the GP service. These included 10 patients presenting with chest pain and seven unwell children. A delay in the initial assessment for those streamed to the GP service $(n=14)$, inadequate assessment including basic observations $(n=13)$, and a lack of understanding of which patients were appropriate for the GP service $(n=7)$ were all described as contributing to events.

"A [ $>65$ year old man] presented at [time] with dizziness and feeling like he was going to collapse. No vital signs recorded by GP streamer. Waited 1 hour to be seen in urgent care centre - when assessed by nurse practitioner heart rate 24 and BP unrecordable. Transferred to resus."

\section{Errors in clinical decision-making}

If patients present to the emergency department with a condition not usually dealt with in primary care (C)

and are seen by a GP who may have inadequate knowledge or skillset for the condition (M)

the patient may be at risk of a mis-management $(\mathrm{O})$

*This was a new theory generated from these data

Clinicians' cognitive biases and the effect of working in a potentially higher risk environment on diagnostic thinking patterns were not documented. Six Coroners' preventing future death reports and 59 NRLS reports

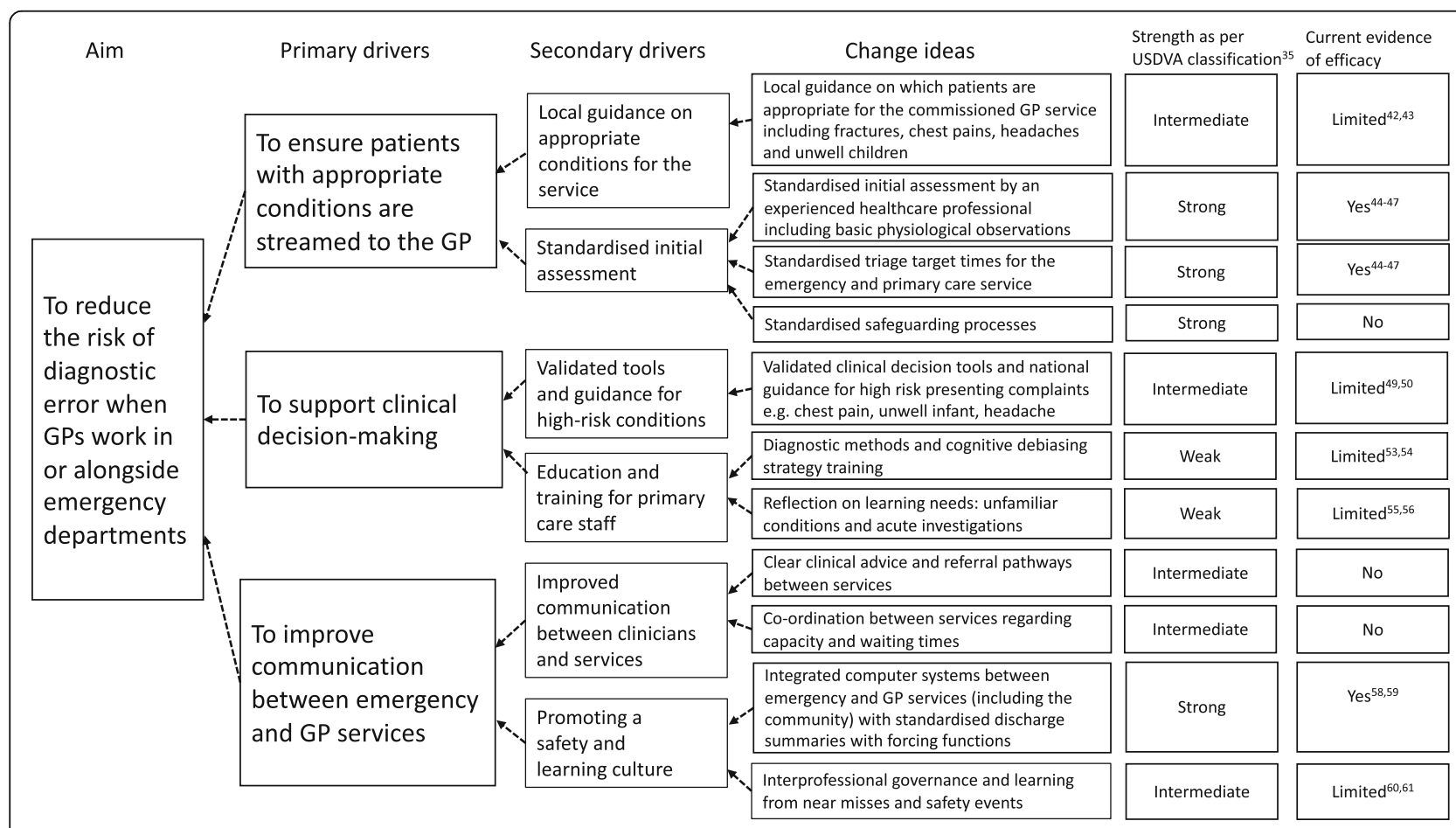

Fig. 2 Driver diagram to show key areas to reduce the risk of diagnostic errors when GP services are located in or alongside emergency departments 
described a lack of referral for urgent investigation. The conditions involved included: 27 fractures (four spinal and three hip fractures), 10 patients presenting with a headache (four following a head injury, four with confirmed subarachnoid haemorrhage), five patients with a deep vein thrombosis, four patients with acute coronary syndrome and four unwell infants.

Some NRLS reports described GPs taking on emergency clinician roles, interpreting acute investigations and managing patients with conditions not usually dealt with in community general practice. Most of these incidents were identified by radiological reporting systems, diagnosing fractures at a later date $(n=$ 87). Others highlighted a lack of knowledge of child safeguarding protocols $(n=5)$ or the clinician's inadequate skillset.

"Patient attended the A\&E department, however seen by the GP placed in the department who examined the patient, ordered an x-ray and then applied a plaster and discharged the patient to fracture clinic. On reviewing the fracture, it was found to be a comminuted fracture of the radial head. This type of fracture would have necessitated an orthopaedic review as they benefit from early surgery. On reviewing the clinical notes no mention of an orthopaedic review was mentioned. It seems that the practitioner concerned does not have the necessary experience to evaluate this type of injury (this is not a primary care type of patient) and should not have managed the patient in the first place."

\section{Inadequate referral pathways and communication between services}

If there is poor communication between the GP service and the emergency department service $(C)$

because of a lack of awareness about capacity (M)

a lack of awareness that investigations have already been requested $(M)$

or inadequate referral pathways $(M)$

then patient assessment and treatment may be delayed $(\mathrm{O})$

*Bold text indicates how this theory was refined from the initial theory in the rapid realist review [6]

Inadequate specialist referral pathways, from the community or emergency department GP services, were described to contribute towards diagnostic errors in one Coroner's preventing future death and 21 NRLS reports. Miscommunication between services about capacity and incompatible computer systems between the emergency department and GP service causing patients to get 'lost' in the system, in some cases leading to delays in treatment were described in another five NRLS reports. Under-staffing was described to contribute towards delayed assessment and diagnosis in one Coroner's and one NRLS report. Another Coroner's report highlighted a case where a lack of communication with community primary care regarding attendances to a walk-in centre possibly contributed towards the death of a baby.

"An infant $[<2$ years $]$ seen by primary care doctor, discharged from PCC at [time 1] and sent back to A\&E. Identified by primary care doctor in letter as unwell, laboured breathing and requiring further assessment and treatment however not referred to paediatricians or informed $A \& E$. As a result the child was not seen until [time 2 - approximately 2.5 hours later] at which point was unwell requiring admission to resus."

\section{Driver diagram}

Our findings are mapped onto a driver diagram which shows the three main sources of unsafe care as the priority areas for change identified from these reports and potential improvement interventions ('change ideas') that would be suitable for evaluation (Fig. 2).

\section{Discussion}

\section{Principal findings}

Nine Coroners' reports (from 1347 community and hospital reports, 2013-2018) and 217 NRLS reports (from 13 million, 2005-2015) were identified describing diagnostic errors with learning relevant to GP service provision in or alongside emergency departments. Initial theories include the following topics as potential priority areas for improvement interventions: inadequate triage and streaming processes; errors in clinical decisionmaking (under-investigation and mis-interpretation of results); and poor communication and referral pathways between the services. High risk presentations included musculoskeletal injury, chest pain, headache, calf pain and sick children.

\section{Strengths and limitations}

There are recognised limitations in analysing these data. Coroners' reports to prevent future deaths only cover the most severe of cases that have led to a patient death so the lessons derived from these cases may not be generalisable to cases with harm but not death outcomes. Analysis of NRLS patient safety incident reports is also limited by under-reporting, selection bias and incomplete analysis of causation [22, 36]. However, patient safety incident reports are recognised by the World Health Organization as useful to analyse the frequency 
of particular sources of harm, describe the nature of incident type and enable causes of harm and potential risks to be explored, supporting this mixed methods approach. Findings can then be used to inform local data collection and quality improvement projects to measure and monitor safe patient care in these settings [37, 38].

Diagnostic errors related to these service models may have been reported through other healthcare providers and therefore not identified through our NRLS filtering process. At the time of this study, NRLS reports were available up to 2015, updated searches may have identified further incident reports, potentially with additional themes indicating areas for improvement. GPs are recognised as low patient safety incident reporters, which may also have contributed to the low number of reports identified [22]. We have not included reports describing diagnostic errors occurring in usual emergency department care - whether GPs make relatively fewer or more errors on the same patients than emergency department staff doctors is unknown. The Cohen's kappa statistic indicates that inter-rater reliability was moderate however this was strengthened by researcher one being an experienced GP and patient safety and qualitative researcher. Stakeholder feedback also strongly supported findings.

However, a strength is that many of the Coroners' reports contained learning from in-depth root cause analysis, and which could be applied to near misses described in the NRLS reports. These two different lenses complement each other for understanding unsafe care, in terms of what happened and perceived causes for both the most serious and other incidents with a range of severity outcomes. Our small sample size is a limitation to the generalizability of our findings but the realist evaluation approach aims to build theory rather than provide definitive answers. Incorporating a realist approach into the thematic analysis of these data, we believe is novel. It structured the process of raising hypotheses to infer how and why these incidents occurred, and look for demiregularities (patterns) to give greater understanding of possible causation. The theories can then be taken forward and tested against qualitative data collected/generated at case study sites with the aim of producing useful, insightful, actionable findings. These insights may also be applied to other new healthcare services where different healthcare providers take on additional roles. Systematic reviews may have identified further interventions to mitigate such events.

\section{Comparison with existing literature}

Other studies support our findings that the causes of diagnostic errors in emergency departments are multifaceted, often with several contributory factors and have potential to result in serious patient harm [16, 39]. The Royal College of Emergency Medicine identified abdominal pain in the elderly, aortic dissection and cervical spine or hip fractures as the top three most common incident reports in emergency medicine following analysis of 61,449 incident reports in 2015 [40]. Our other work involved analysis of 2288 NRLS reports over a two year period (20132015) and described fracture (notably cervical spine and hip fractures), myocardial infarction and intracranial bleed as the most common diagnostic errors [25]. High-risk conditions for diagnostic errors described in community general practice do not include musculoskeletal injuries, headaches or veno-thrombotic events, [41] which may reflect the different cohort of patients (and 'pre-test' levels of risk) seen in these settings.

There is little national guidance on which patients should be streamed to GP services and this will depend on local service provision [42]. Initial NHS England guidance has adopted a model which advises against streaming patients with traumatic or head injuries and includes specific guidance for those presenting with chest pain, nosebleeds and feverish children [43]. There are however, established and internationally recognised triage systems which can help identify seriously ill patients who require urgent medical attention [44, 45]. Early warning scores for unwell children are available, [46] with more recent tools incorporating clinician 'gut instinct' and use by GPs [47]. The 'Gestalt' decision-making of senior nursing staff may also be better than algorithmic methods [48]. Our findings suggest that all patients who present to emergency departments, for the emergency or GP service, should be subject to a prompt standardised initial assessment, including basic observations.

The evidence for validated clinical decision-making tools in this setting is limited. Recognised tools to assess low risk chest pain include ECG and biochemical investigation results that may not be available to GPs working in emergency departments $[49,50]$ There are no validated risk assessment tools to assess patients presenting to the emergency department with headache, and the difficulty in identifying the few that do have a subarachnoid haemorrhage is acknowledged $[51,52]$. Diagnostic cognitive processes and the effects of simplifying rules, short cuts or heuristics to replace more complex procedures are well described [53]. GPs that usually work in a lower risk community setting where there are often lower perceived and actual pre-test probabilities of serious disease may be at risk of errors in risk estimation. Cognitive debiasing strategies, [54] and reflective practice, [55] have been tried but their effectiveness in practice is questionable [56].

Poor communication and inadequate referral pathways between GP and specialist care are known to contribute towards patient safety incidents and can be targeted on a local level. Child safeguarding 
referral processes should be standardised between GP and emergency services [57]. Integrated computer systems including timely mandatory forcing functions for key information can improve communication [58, 59].

The lack of patient safety research in this area should be highlighted, $[6,20,21]$ and teams should continue to learn from diagnostic errors, near misses and other patient safety incidents through local and national level reporting systems $[60,61]$.

\section{Implications for research and/or practice}

Service providers and individual emergency departments will adopt a GP service model depending on their local circumstances and context [14]. Since this work was conducted, urgent and emergency care services along with almost all NHS service provision have changed due to the Covid-19 pandemic, including telephone screening of emergency department walk-in attendances, [62] and remote GP consultations [63]. Recommendations to improve future practice summarised in the driver diagram could however still be applied to these evolving healthcare service models. Implementation of the new Emergency Care Dataset (ECDS) in England, with the intent to extend soon into Ambulance and Integrated Urgent Care will ensure that in future there will be improved quantitative data to identify both presenting conditions and outcomes in patients who access Urgent and Emergency Care services to improve understanding of diagnostic errors in these settings. With better such data, the necessary evaluations of improvement interventions will be more feasible. These theories require refinement and testing with qualitative data collection from case study (hospital) sites.

\section{Conclusion}

Initial theories include the following topics as potential priority areas for improvement interventions and evaluation to minimise the risk of diagnostic errors when GPs work in or alongside emergency departments: a standardised initial assessment with streaming guidance based on local service provision; clinical decision support for high-risk conditions; and standardised computer systems, communication and referral pathways between emergency and GP services.

\section{Abbreviations}

GP: General Practitioner; ED: Emergency Department

\section{Acknowledgements}

The authors would like to thank GPs in EDs study team members (Freya Davies, Michelle Edwards, Julie Hepburn, Bridie Evans, Pippa Anderson, Delyth Price) for feedback and contributions towards this work. Also, Stuart Hellard for assisting with the database searches and Joanne Hyam for pilot work.

\section{Patient involvement}

Patient contributors Julie Hepburn and Bridie Evans, both co-applicants on the GPs in EDs wider study, contributed to discussions on findings and dissemination of this work.

RAMESES reporting standards for realist evaluation checklist

This has been completed and uploaded as supplementary material to confirm methods were carried out in accordance with relevant guidelines.

\section{Authors' contributions}

AC, AE, ACS, NS, LD, PH, MC, HS and TH are co-applicants on the wider project and were involved in the conceptualisation of this study. AC screened and coded all Coroners' and NRLS reports, FH double coding. AC prepared the first draft of the manuscript which was reviewed and critically appraised by all authors. All authors read and approved the final manuscript.

\section{Funding}

This work was supported by the National Institute for Health Research HS\&DR Project 15/145/04. The views expressed are those of the authors and not necessarily those of the NIHR or the Department of Health and Social Care.

\section{Availability of data and materials}

NRLS data is not publicly available due to the data sharing agreement at Cardiff University. The 'Coroners reports to prevent future deaths' dataset is available on the Courts and Tribunals Judiciary Website, https://unw.judiciary.uk/related-offices-andbodies/office-chief-coroner/https-www-judiciary-uk-subject-community-health-careand-emergency-services-related-deaths/

\section{Declarations}

\section{Ethics approval and consent to participate}

Aneurin Bevan (Gwent, Wales, UK) University Health Board's Research Risk Review Committee approved research protocols for analysis of National Reporting and Learning System (NRLS) patient safety incident reports and judged the study as using anonymised data for service improvement purposes, approving it on this basis (ABHB R\&D Ref number: SA/410/13). Analysis of NRLS reports was also reviewed as part of the wider "GPs in EDs" study (National Institute for Healthcare Research HS\&DR: 15/145/04) and given a favourable ethical opinion on $23 / 11 / 17$ by the Wales Research Ethics Committee (REF: 17/WA/03). No ethical approval was sought for analysis of the Coroners reports since these are publicly available data.

\section{Consent for publication}

Not applicable.

\section{Competing interests}

The authors declare they have no competing interests.

\section{Author details}

'Division of Population Medicine, School of Medicine, Cardiff University, Cardiff, UK. ² University of Warwick, Coventry, UK. ${ }^{3}$ Macquarie University, Sydney, Australia. ${ }^{4}$ John Radcliffe Hospital, Oxford, UK. ${ }^{5}$ University of Lincoln, Lincoln, UK. ${ }^{6}$ Swansea University, Swansea, UK. 7 London School of Hygiene and Tropical Medicine, London, UK.

Received: 16 April 2021 Accepted: 24 October 2021

Published online: 18 November 2021

\section{References}

1. NHS Five Year Forward View 2014. https://www.england.nhs.uk/wp-content/ uploads/2014/10/5yfv-web.pdf

2. A\&E departments to get more funding 2017. https://www.gov.uk/ government/news/ae-departments-to-get-more-funding

3. Trzeciak S, Rivers E. Emergency department overcrowding in the United States: an emerging threat to patient safety and public health. Emerg Med J. 2003;20(5):402-5. https://doi.org/10.1136/emj.20.5.402.

4. Richardson D. Increase in patient mortality at 10 days associated with emergency department overcrowding. MJA. 2006;184(5):213-6. https://doi. org/10.5694/j.1326-5377.2006.tb00204.x. 
5. Cooper A, Carson-Stevens A, Hughes T, Edwards A. Is streaming patients in emergency departments to primary care services effective and safe? BMJ. 2020;368:8-11. https://doi.org/10.1136/bmj.m462.

6. Cooper A, Davies F, Edwards M, Anderson P, Carson-Stevens A, Cooke MW, et al. The impact of general practitioners working in or alongside emergency departments: a rapid realist review. BMJ Open. 2019;9(4):1-11. https://doi.org/10.1136/bmjopen-2018-024501.

7. Dale J, Reid F, Green J, et al. Primary care in the accident and emergency department: I. prospective identification of patients. BMJ. 1995;311(7002): 423-6. https://doi.org/10.1136/bmj.311.7002.423.

8. Ward P, Huddy J, Hargreaves S, Touquet R, Hurley J, Fothergill J. Primary care in London: an evaluation of general practitioners working in an inner city accident and emergency department. J Accid Emerg Med. 1996;13(1): 11-5. https://doi.org/10.1136/emj.13.1.11.

9. Emergency departments: More useful than the official data suggests. The College of Emergency Medicine. 2014. http://www.kingstoned.org/uploa ds/2/4/0/2/24023085/ca_past_paper.pdf

10. Smith L, Narang Y, Pavon A et al. To GP or not to GP: evaluation of children triaged to see a GP in a tertiary paediatric emergency department. BMJ Qual Saf 2017;0:1-8.

11. Coleman $\mathrm{P}$, Irons $\mathrm{R}$, Nicholl J. Will alternative immediate care services reduce demands for non-urgent treatment at accident and emergency. Emerg Med J. 2001;18(6):482-7. https://doi.org/10.1136/emj.18.6.482.

12. Nagree $Y$, Camarda V. Fatovich D et al. Quantifying the proportion of general practice and low-acuity patients in the emergency department. 2013;198(June):612-5. https://doi.org/10.5694/mja12.11754.

13. Thompson MIW, Lasserson D, Mccann L, et al. Suitability of emergency department attenders to be assessed in primary care : survey of general practitioner agreement in a random sample of triage records analysed in a service evaluation project. BMJ Open. 2013;3:e003612.

14. Cooper A, Edwards M, Brandling J, Carson-Stevens A, Cooke M, Davies F, Hughes T, Morton K, Siriwardena A, Voss S, Benger J, Edwards A Taxonomy of the form and function of primary care services in or alongside emergency departments: concepts paper. Emerg Med J 2019;0:1-6, 36, 10, https://doi.org/10.1136/emermed-2018-208305.

15. Leape LL, Brennan TA, Laird N, Lawthers AG, Localio AR, Barnes BA, et al, The nature of adverse events in hospitalized patients. N Engl J Med. 1991 324(6):377-84. https://doi.org/10.1056/NEJM199102073240605.

16. Berner ES, Graber ML. Overconfidence as a cause of diagnostic error in medicine. Am J Med. 2008;121(5):S2-23. https://doi.org/10.1016/j.amjmed.2 008.01.001.

17. Diagnostic Errors: Technical series on safer primary care World Health Organization. 2016. p. 3. https://www.who.int/teams/integrated-healthservices/patient-safety/research/safer-primary-care.

18. Dale J, Green J, Reid F, Glucksman E, Higgs R. Primary care in the accident and emergency department: II. Comparison of general practitioners and hospital doctors. BMJ. 1995;311(7002):427-30. https://doi.org/10.1136/ bmj.311.7002.427.

19. Croskerry P, Norman G. Overconfidence in clinical decision making. Am J Med. 2008;121(5 SUPPL):24-9. https://doi.org/10.1016/j.amjmed.2008.02.001.

20. Goncalves-Bradley D, Khangura JK, Flodgren G, et al. Primary care professionals providing non-urgent care in hospital emergency departments. Cochrane Database Syst Rev. 2018;2(2). https://doi.org/10.1 002/14651858.CD002097.pub4.

21. Ramlakhan S, Mason S, O'Keeffe C, et al. Primary care services located with EDs: a review of effectiveness. Emerg Med J. 2016;33(7):495-503. https://doi. org/10.1136/emermed-2015-204900.

22. Carson-Stevens A, Hibbert $\mathrm{P}$, Williams $\mathrm{H}$, et al. Characterising the nature of primary care patient safety incident reports in the England and Wales National Reporting and Learning System: a mixed-methods agenda setting study for general practice. NIHR HS\&DR. 2016;4(27):1-76. https:/wnw.journalslibrary.nihr.ac.uk/hsdr/hsdr042 70\#/abstract. https:/doi.org/10.3310/hsdr04270.

23. Donaldson $\sqcup$, Panesar SS, Darzi A. Patient-safety-related hospital deaths in England thematic analysis of incidents reported to a National Database. PLoS Med. 2014; 11(6):e1001667. https://doi.org/10.1371/journal.pmed.1001667.

24. Rees P, Edwards A, Panesar S, Powell C, Carter B, Williams H, et al. Safety Incidents in the Primary Care Office Setting. Pediatrics. 2015;135(6):135(6)1035. https://doi.org/10.1542/peds.2014-3259.

25. Hussain F, Cooper A, Carson-Stevens A, Donaldson L, Hibbert P, Hughes T, et al. Diagnostic error in the emergency department: learning from national patient safety incident report analysis. BMC Emerg Med. 2019;19(1):1-9. https://doi.org/10.1186/s12873-019-0289-3.

26. Edwards A et al. Evaluating effectiveness, safety, patient experience and system implications of different models of using GPs in or alongside Emergency Departments. NIHR HS\&DR - 15/145/04. https://www.journa Islibrary.nihr.ac.uk/programmes/hsdr/1514504\#/.

27. Pawson R. Evidence-based policy: SAGE Publications Ltd London; 2006. https://doi.org/10.4135/9781849209120

28. Pawson R, Tilley N. Realistic evaluation. London: SAGE Publications; 1997.

29. Coroners and Justice Act 2009. Chapter 25 http://www.legislation.gov.uk/ ukpga/2009/25/contents

30. Courts and Tribunals Judiciary. Reports to Prevent Future Deaths. https:// www.judiciary.uk/related-offices-and-bodies/office-chief-coroner/https-wwwjudiciary-uk-subject-community-health-care-and-emergency-services-relateddeaths/.

31. National Reporting and Learning System. 2017. https://report.nrls.nhs.uk/ nrlsreporting/.

32. Conceptual Framework for the International Classification for Patient Safety. 2009. p. 18. https://www.who.int/patientsafety/taxonomy/icps_full_report. pdf.

33. What is diagnostic error? Society to Improve Diagnosis in Medicine. 2019. https://www.improvediagnosis.org/what-is-diagnostic-error/.

34. Bennett B, Provost L. What's your theory? 2015. p. 38. http://www.apiweb. org/QP_whats-your-theory_201507.pdf.

35. Root Cause Analysis Tools US Department of Veterans Affairs National Center for Patient Safety. 2020. https://www.patientsafety.va.gov/docs/RCA Guidebook_10212020.pdf.

36. Carson-Stevens A, Hibbert P, Avery A, Butlin A, Carter B, Cooper A, et al. A cross-sectional mixed methods study protocol to generate learning from patient safety incidents reported from general practice. BMJ Open. 2015;5: e009079. https://doi.org/10.1136/bmjopen-2015-009079.

37. Patient Safety Incident Reporting and Learning Systems World Health Organization; 2020. p. 5-9. https://apps.who.int/iris/rest/bitstreams/1303416/ retrieve.

38. Global patient safety action plan 2021-2030. p. 9-10. https://www.who.int/ teams/integrated-health-services/patient-safety/policy/global-patient-safety-a ction-plan.

39. Kachalia A, Gandhi TK, Puopolo AL, Yoon C, Thomas EJ, Griffey R, et al. Missed and Delayed Diagnoses in the Emergency Department: A Study of Closed Malpractice Claims From 4 Liability Insurers. Annals of Emergency Medicine. 2007;49(2):196-205.

40. Redfern E, Boyle A. Mcintyre S. RCEM: The top ten significant incident reports in emergency medicine; 2016. p. 1-2. https://res.cloudinary.com/ studio-republic/images/v1635671915/Top10_significant_incidents_EDs_201 6/Top10_significant_incidents_EDs_2016.pdf?_i=AA.

41. Singh H, Schiff GD, Graber ML, Onakpoya I, Thompson MJ. The global burden of diagnostic errors in primary care. BMJ Qual Saf. 2017;26(6):484-94 https://doi.org/10.1136/bmjqs-2016-005401.

42. RCEM: Initial Assessment of Emergency Department Patients 2017 https:// www.rcem.ac.uk/docs/SDDC Intial Assessment (Feb 2017).pdf.

43. Primary care streaming: Roll out to September 2017 NHS England 2017. https://castlepointandrochfordccg.nhs.uk/about-us/our-governing-body/ governing-body-meetings/2017/27-july-2017/2801-item-07ii-primary-carestreaming-appendix-270717/file.

44. Cooke MW, Jinks S. Does the Manchester triage system detect the critically ill ? Emerg Med J. 1999;16(3):179-81. https://doi.org/10.1136/emj.16.3.179.

45. Fitzgerald $G$, Jelinek $G$, Scott $D$, et al. Emergency department triage revisited. Emerg Med J. 2010;27(2):86-92. https://doi.org/10.1136/emj.2009. 077081.

46. Roland D. Paediatric early warning scores: holy grail and Achilles ' heel. Arch Dis Child Educ Pr Ed. 2012;97(6):208-15. https://doi.org/10.1136/a rchdischild-2011-300976.

47. Roland D, Lewis G, Fielding P, Hakim C, Watts A, Davies F. The Paediatric observation priority score : a System to aid detection of serious illness and assist in safe discharge. Open J Emerg Med. 2016;4(02):38-44. https://doi. org/10.4236/ojem.2016.42006.

48. Iversen AKS, Kristensen M, Østervig RM, Køber L, Sölétormos G, Lundager Forberg J, et al. A simple clinical assessment is superior to systematic triage in prediction of mortality in the emergency department. Emerg Med J. 2019:36(2):66-71. https://doi.org/10.1136/emermed-2016-206382. 
49. Cohen M, Bernink PJLM, Mccabe CH, et al. The TIMl risk score for unstable angina / non - ST elevation MI. JAMA. 2000;284(7):835-42. https://doi.org/1 0.1001/jama.284.7.835.

50. Chest pain: Low Risk Rule-Out Pathways. RCEM Learning.

51. Edlow JA. Diagnosis of subarachnoid hemorrhage. Neurocrit Care. 2005;2(2): 99-109. https://doi.org/10.1385/NCC:2:2:099.

52. Edlow JA, Caplan LR. Avoiding pitfalls in the diagnosis of subarachnoid hemorrhage. N Engl J Med. 2000;342(1):29-36. https://doi.org/10.1056/ NEJM200001063420106.

53. Elstein A, Schwarz A. Clinical problem solving and diagnostic decision making: selective review of the cognitive literature. BMJ. 2002;324(7339): 729-32. https://doi.org/10.1136/bmj.324.7339.729.

54. Croskerry P. Cognitive forcing strategies in clinical decisionmaking. Ann Emerg Med. 2003;41(1):110-20. https://doi.org/10.1067/mem.2003.22.

55. Mamede S, Schmidt H, Rikers R. Diagnostic errors and reflective practice in medicine. J Eval Clin Pract. 2007;13(1):138-45. https://doi.org/10.1111/j.13 65-2753.2006.00638.x.

56. O'Sullivan ED, Schofield SJ. A cognitive forcing tool to mitigate cognitive bias - a randomised control trial. BMC Med Educ. 2019;19(1):1-8. https://doi. org/10.1186/s12909-018-1444-3.

57. Sidebotham P, Biu T, Goldsworthy L. Child protection procedures in emergency departments. EMJ. 2007;24(12):831-5. https://doi.org/10.1136/ emj.2007.051011.

58. Kripalani S, LeFevre F, Phillips CO, Williams MV, Basaviah P, Baker DW. Deficits in communication and information transfer between hospital-based and primary care physicians. JAMA. 2007;297(8):831-41. https://doi.org/10.1 001/jama.297.8.831.

59. Williams H, Edwards A, Hibbert P, Rees P, Prosser Evans H, Panesar S, et al. Harms from discharge to primary care: mixed methods analysis of incident reports. Br J Gen Pract. 2015;65(641):e829-37. https://doi.org/10.3399/bjgp $5 \times 687877$.

60. Mahajan RP. Critical incident reporting and learning. Br J Anaesth. 2010; 105(1):69-75. https://doi.org/10.1093/bja/aeq133.

61. Williams H, Cooper A, Carson-Stevens A. Opportunities for incident reporting. Response to: 'The problem with incident reporting' by Macrae et al. BMJ Qual Saf. 2016;25(2).

62. Discombe M. NHSE launches pilots to shake-up A\&E model; HSJ 2020. https://www.hsj.co.uk/coronavirus/nhse-launches-pilots-to-shake-up-aandemodel/7027943.article.

63. Greenhalgh T, Koh GCH, Car J. Covid-19: a remote assessment in primary care. BMJ. 2020;368:m1182. https://doi.org/10.1136/bmj.m1182.

\section{Publisher's Note}

Springer Nature remains neutral with regard to jurisdictional claims in published maps and institutional affiliations.

Ready to submit your research? Choose BMC and benefit from:

- fast, convenient online submission

- thorough peer review by experienced researchers in your field

- rapid publication on acceptance

- support for research data, including large and complex data types

- gold Open Access which fosters wider collaboration and increased citations

- maximum visibility for your research: over $100 \mathrm{M}$ website views per year

At $\mathrm{BMC}$, research is always in progress.

Learn more biomedcentral.com/submissions 